\title{
Notas sobre la fortuna de Armando Palacio Valdés en la prensa de la Edad de Plata
}

\author{
Carmen SERVÉN DÍEZ \\ Universidad Autónoma de Madrid
}

\begin{abstract}
RESUMEN
En el primer tercio del siglo XX, Don Armando Palacio Valdés es un autor extraordinariamente conocido. Pero su figura pública resulta muy controvertida. Se da la paradoja de que este novelista, que fue considerado un radical peligroso y disolvente por la prensa católica del último cuarto del siglo XIX (Servén), es recomendado ahora (Fernández Cifuentes) en círculos conservadores pero execrado por los intelectuales jóvenes. Capítulo aparte merece su fortuna entre las lectoras, que le dedican repetidos homenajes y lo consideran adalid de las mujeres. El trabajo procura fijar la presencia de Don Armando en medios de prensa de diverso carácter, lo que muestra la existencia en la Edad de Plata de un público diversificado que maneja evaluaciones literarias diferentes e incluso encontradas. Una revisión actual de la proyección cultural del novelista asturiano debe contemplar su desigual fortuna en la prensa de la Edad de Plata
\end{abstract}

Palabras clave: Edad de Plata, Prensa, Diversificación del público, Lectoras

\begin{abstract}
In the first third of the twentieth century, Don Armando Palacio Valdés is an extremely well-known author. But his very controversial public figure. The paradox is that this novelist, who was considered a dangerous radical and solvent for the Catholic press in the last quarter of the nineteenth century (Serven), is now recommended (Fernández Cifuentes) in conservative circles but detested by the young intellectuals. Deserves a chapter of his fortune to the readers, who will spend it as repeated tributes and champion of women. The work seeks to establish the presence of Don Armando in media of diverse character, which shows the existence in the Edad de Plata of diverse audiences that handles various literary reviews and even found. A current review of cultural projection of the novelist Spaniard should consider their unequal fortune in the press of the Silver Age
\end{abstract}

Keywords: Edad de Plata, Newspapers, Diversification of the public, Women Readers

La recepción de la obra narrativa producida por Armando Palacio Valdés ha atravesado periodos de entusiasmo público que han venido a desembocar en un olvido generalizado. En los últimos años, el renovado interés que Laviana y Entralgo (Asturias) están promoviendo, los actos conmemorativos en Avilés, y la importante labor de quienes dirigen la casa-museo del escritor, así como el trabajo 
sin desmayo de estudiosos como Guadalupe Gómez Ferrer, Brian Dendle o José Luis Campal, por no hablar de Francisco Trinidad que coordina los esfuerzos de otros especialistas, han conducido a una recuperación del escritor.

El insigne novelista mereció tempranamente la atención de revistas especializadas en estudios filológicos o literarios; pero su fortuna en la prensa de interés general, en diarios y revistas dirigidas al público heterogéneo, fue muy variable. Seguramente no es ajeno a ello ese viraje de que hablan sus biógrafos: a lo largo de los años noventa del siglo XIX, Palacio Valdés sufre una crisis personal que desemboca en lo que él consideró su conversión en 1899 y su postura religiosa cambió perceptiblemente (Gómez Ferrer, "Armando Palacio Valdés y la civilización...” 148).

\section{La cuestión religiosa}

En su juventud, Palacio Valdés fue un liberal convencido, que se dejó seducir por la doctrina krausista y simpatizó con la Institución Libre de Enseñanza. Pero por entonces tenía un peso importante el pensamiento tradicional, integrista y basado en la intransigencia (Gómez Ferrer, "Armando Palacio Valdés y la civilización..." 144); el joven escritor no compartía en absoluto ni las posiciones políticas que mantenía la Iglesia española ni sus recelos ante la ciencia. De modo que en sus obras encontramos una sensibilidad social y una perspectiva sobre la cuestión religiosa que hubieron de escocer a sectores sociales muy conservadores. La postura del escritor al respecto se manifiesta en obras como Marta y María o La $f e$. En la primera transparenta el hecho de que "el integrismo hizo inviable la existencia de un catolicismo liberal" y fanatizó a ciertos sectores sociales; en la segunda se muestra la incapacidad del clero para asumir los cambios científicos y sociales (Gómez Ferrer, “Armando Palacio Valdés y la civilización...” 154 y 157).

Claro está que su punto de vista fue objeto de rechazo en las revistas culturales de tipo confesional católico. Así, La Ilustración Católica, de inspiración muy conservadora en sus evaluaciones y que gozó de larga permanencia (1877-1894), afirmó sin paliativos que Galdós y Palacio Valdés luchaban contra la Iglesia; los consideraba "literatos racionalistas", "que pueden ser impunemente tendenciosos" y cuyo éxito muestra la enorme proyección de una crítica liberal a la que los católicos no deben hacer ningún caso (Bachiller Alonso, La Ilustración Católica 31-I-1892).

La oposición de las revistas y medios confesionales a las corrientes realnaturalistas en el último cuarto del siglo XIX ha sido comentada por los estudiosos actuales. A lo largo de los debates que dieron paso al triunfo del realismo, los intelectuales españoles se refirieron repetidamente a la crisis de ideales que observaban en la sociedad coetánea (Oleza 264-5). Precisamente, el intento de 
recuperar el ideal sigue impregnando la crítica confesional en años subsiguientes (Servén Díez, "La Ilustración Católica...” 228, 232).

Son años en que la crítica católica española sigue reclamando un ideal para el arte $^{1}$, mientras Zola en Francia capitanea una escuela que dice abominar del ideal, considerándolo raíz de todos los sueños peligrosos. Desde la óptica de Zola y de los naturalistas, el ideal propicia nocivos espejismos; los personajes de muchas novelas son "bribones" para quienes "el ideal es un velo detrás del cual pueden permitírselo todo" (Zola 104). Precisamente, ese intento de verismo y de ajustar la óptica narrativa a la realidad, que es característica esencial del naturalismo, se percibe especialmente en novelas de Galdós publicadas en la década de 1880, y en obras de Palacio Valdés de la misma época.

El divorcio entre Armando Palacio Valdés y la crítica integrista del último cuarto de siglo XIX deja su huella en las evaluaciones que ciertos clérigos emprenden en el que consideran peligroso ámbito de las lecturas de ficción. El padre Ladrón de Guevara, en su revisión Novelistas malos y buenos, que tuvo varias ediciones $^{2}$, considera que D. Armando es "malo por ambos lados. Es incrédulo"; rechaza Marta y Maria ("rechifla de la piedad"), El idilio de un enfermo ("malsana"), La espuma ("peligrosa"), La fe ("defensa del ateísmo")...

Como ya se ha dicho más arriba, a fines de los noventa el escritor resuelve su profunda crisis personal mediante una "conversión"; el resultado más evidente es que da por superada su cáustica perspectiva anterior y entra en una fase en que la caridad cristiana y las gentes de buena voluntad presiden sus obras; la religiosidad es analizada ya de manera más benevolente, como en Santa Rogelia. A ello se une el que su actitud hacia la problemática social se va modificando desde principios del siglo XX. Guadalupe Gómez Ferrer ha hablado de una "anestesia de reflejos sociales" que sufriría el escritor y que se hace patente en Sinfonía pastoral (“Armando Palacio Valdés y la civilización..." 164); y la atribuye más que a hechos biográficos del escritor al proceso sufrido por la sociedad española: con miedo al socialismo y al desorden, las clases medias cancelan su demofilia anterior (164).

Así, hay un viraje en el talante de Palacio Valdés, que se acompaña de un proceso de cambio en la sociedad española. Como resultado, la obra del novelista es objeto de nuevas estimaciones por parte de la crítica confesional. En los años veinte, Carlos María Abad dedica un largo artículo de la revista Razón y fe a

1 "Lo deforme, lo brutal, lo bajo, lo irreverente y lo inmundo han invadido los puros y honrados dominios del arte [...] Falta al mundo del arte un ideal común", "Porque careciendo de amor al ideal, el público y la crítica menuda, su cómplice, huyen de todo lo que puede elevar el alma y van tras de todo lo que puede halagar los sentidos" decía Valentín Gómez en la revista La Ilustración Católica ya el 5-IV-86.

${ }^{2}$ Veo la de 1933, pero la Biblioteca Nacional de Madrid conserva otras dos: de 1910 y de 2001. 
considerar de nuevo a la luz del criterio católico la obra del narrador asturiano. Reconoce que el padre Francisco Blanco García rechazó alguna de sus primeras novelas, pero insiste en que Armando Palacio Valdés es un novelista católico, aunque Marta y María, La hermana San Sulpicio y La fe hayan sido muy discutidas a este respecto en el pasado. Y evoca el aviso estampado por el autor al frente de las nuevas ediciones de Marta y María:

\begin{abstract}
"No he querido en la presente obra herir al misticismo verdadero ni ridiculizar la vida contemplativa...o obstante, como algunas personas piadosas han creido ver en el libro menosprecio de la vida contemplativa y burla de las gracias sobrenaturales que Dios ha operado en algunas santas que la Iglesia venera, y como realmente, al arrojar ìedras sobre el falso misticismo, pude haber salpicado al verdadero, cúmpleme declarar que, si esto ha sucedido, lo deploro. No doy a ninguna de las palabras contenidas en mi libro otra significación que la que puede acordarse con la fe cristiana y con las enseñanzas de la Iglesia Católica, a las cuales me glorío de vivir sometido" (apud Abad 47).
\end{abstract}

Pese a tan tajante y exculpatoria declaración de intenciones, no son esas primeras obras -admite el P. Abad- las que caracterizan a Palacio como novelista católico, sino las más recientes, en que los sentimientos cristianos del autor afloran y hacen triunfar el optimismo cristiano, el perdón, la oración y la resignación. Así en Tristán o el pesimismo, en que el personaje Germán Reynoso practica la resignación y se vuelve hacia Dios cuando lo golpea el dolor; pero también en Los papeles del Doctor Angélico, Años de juventud del Doctor Angélico y La novela de un novelista, que transparentan su carácter autobiográfico, aunque no usen la primera persona narrativa.

Poco después de fallecer el novelista, en 1938, otro religioso le dedica una larga semblanza personal y literaria en la misma revista Razón y fe: E. Fernández Almuzara, que considera demostrado por el P. Abad el catolicismo del asturiano y aún va más lejos al afirmar que la estructura profunda de las obras de Palacio Valdés tiene un firme sentido religioso: "A nadie extrañará, pues, que yo diga que su obra literaria tiene un hondo contenido religioso y moral, que es como el armazón, el sostén y la arquitectura de ella" (Fernández Almuzara 426).

Fernández Almuzara evoca de nuevo las palabras escritas por el P. Blanco García décadas atrás, pero recuerda que ya aquel estudioso anotaba las "capitales restricciones" con que Armando Palacio Valdés participó de las corrientes naturalistas, y procura hacer hincapié en que las novelas más recientes del autor están saturadas "por lo general de un sano realismo" (431); glosa además el carácter nacional a la par que universal de su arte (432) y lo dibuja como escritor afin al "Alzamiento Nacional" (434), independiente, armónico, ajeno a las modas, patriota y religioso.

Como es evidente, los medios confesionales católicos han fluctuado en sus apreciaciones de la obra novelística del escritor a lo largo de la vida de éste. Poco a 
poco se pasó del vituperio indignado al aplauso rendido. En la actualidad, Etelvino González López acaba de hacer una edición de $L a$ fe en cuya presentación defiende la consideración Palacio Valdés como novelista católico y asegura que esta novela, repetidamente interpretada en el pasado como un ataque a la Iglesia, es en realidad una obra profundamente comprometida con la espiritualidad cristiana.

\section{El patriarca de las letras y los jóvenes escritores}

En la primera década del siglo XX, a comienzos de la llamada Edad de Plata, Palacio Valdés es un novelista consagrado. Gregorio Martínez Sierra asegura en $L a$ Lectura (pp. 401-3, nº1, 1903) que el novelista tiene mucho público en España, pero discreto y callado; Miguel de Unamuno, en sus palabras de contribución al homenaje que al asturiano tributa la Universidad de Oviedo, lo considera uno de los más "gustosos" escritores españoles:

"En nuestra literatura no abunda, ni mucho menos, la nota íntima y recojida (sic), el tono de apacible entrañabilidad. Casi todo es exterior, y casi todo, en el fondo, violento. Y así me explico que Palacio Valdés se uno de nuestros escritores más gustosos, de los de hoy el más gustado tal vez, en países donde es una verdad efectiva la vida del hogar y donde los hombres saben recogerse en él mejor que nosotros" (1109).

Así, don Armando es ya un novelista de éxito público en el periodo de entresiglos, no sólo en España, sino también en otros países, como apunta Unamuno. Sobre su presencia destacada en la prensa norteamericana, han trabajado Ángel Capellán y Mercedes Caballer, que analizan la relación específica del novelista español con el escritor norteamericano William D. Howells, pero también recogen su importante presencia en artículos y revistas gracias a plumas ajenas a la de su amigo.

Sin embargo, ya en 1901 La España Moderna (1-VII-1901, p. 116), importante revista literaria, considera la emergencia de una nueva generación; distingue dos grupos de escritores, dos oleadas cronológicamente sucesivas: por una parte la que forman Valera, Pereda, Palacio Valdés, Galdós..., y por otra la integrada por Blasco Ibáñez o Unamuno. A ojos vista, don Armando ya no es un escritor de última hornada.

De hecho, son años en que algún crítico lo coloca a la cabeza de la novela española. Augusto Martínez Olmedilla, en la importante revista Nuestro tiempo (oct 1904, p. 24) asegura que La aldea perdida acaba de ser un sonado éxito y afirma que su autor "es el primer novelista español contemporáneo".

Y como "maestro" será considerado por otros autores y críticos más jóvenes que él en años posteriores; en los años veinte, dice Azorín que nuestro país "cuenta con una pléyade brillante de novelistas a cuyo frente se halla el grande y querido maestro Don Armando Palacio Valdés" ("Requiem Aeternam", en $A B C$ 19-2-24, 
p. 7). En esa misma década, parece que es Andrés González Blanco quien le aplicó y lanzó una expresión que hará fortuna: "El patriarca de la novela española. Don Armando Palacio Valdés" (a propósito de su última novela, en Nuestro Tiempo, $\mathrm{n}^{\circ}$ 308, agosto de 1924, p. 51); muerto Galdós, este crítico afirma que el asturiano es nuestro "primer novelista" (ídem). En otro lugar, el mismo González Blanco insiste en que Don Armando es "maestro indiscutible de la novela en nuestros días" (Nuestro tiempo, $\mathrm{n}^{\mathrm{o}} 300$, Diciembre de 1923, p. 3).

El escritor se había convertido en un hombre mayor cuyo aspecto físico y talante apacible lo caracterizan como amable patriarca; en periódicos y revistas italianos, norteamericanos o españoles se habla del "patriarca de la novela" o del "patriarca de las letras españolas"; probablemente, el iniciador de esa óptica sobre el autor, como he dicho más arriba, fue Andrés González Blanco en la revista Nuestro tiempo de 1924; pero le siguieron otros, seducidos por la apacible escritura del novelista y por su imagen personal, pulcra y luminosa, con su pelo blanquísimo y sus ojos azules: en los años veinte, Hymen Alpern, Lucio Ambruzzi o Matilde Muñoz, proclaman en los títulos de sus artículos esa identificación de Armando Palacio Valdés con un patriarca de las letras ${ }^{3}$.

Pero muchos intelectuales jóvenes, menos benevolentes, lo consideran un vestigio del pasado por esos mismos años ${ }^{4}$. En los años veinte escribe también una nueva promoción de autores, nada elogiosos en lo que respecta a la obra de Palacio Valdés. La Gaceta Literaria, dirigida por Giménez Caballero, es la revista que arropa a la nueva literatura y en sus páginas jóvenes como Concha Méndez, Rosa Chacel, Cesar M. Arconada o Antonio Espina, exhiben su desinterés o rechazo hacia la obra del novelista asturiano. Al ser interrogada sobre el particular, Concha Méndez explica:

"No puedo emitir opinión alguna sobre don Armando Palacio Valdés, porque de las dos obras suyas que comencé a leer, ninguna me fue posible terminarla".

César M. Arconada tiene también dificultades para leer al patriarca:

“ Hace tiempo comencé a leer una novela de Palacio Valdés y no pude pasar de la décima página. Hoy- estoy seguro- no podría pasar de la primera. Debe ser un gran novelista. Yo no lo sé”.

Concha Albornoz tampoco piensa contarse entre sus lectores:

"No he leído ninguno de sus libros, ni pienso leerlos en mi vida".

3 Véanse las referencias correspondientes en la bibliografía de Campal.

${ }^{4}$ Ya se fijó en ello Luis Fernández Cifuentes, pp. 274-7. 
Rosa Chacel lo siente completamente ajeno y lejano:

"No conozco nada de ese autor. Recientemente he tenido la sorpresa de saber que pertenece a nuestro siglo".

Antonio Espina, incluso toma una actitud agresiva:

"Da lástima que don Armando Palacio Valdés sea un excelente caballero - de la barba gris - anciano y tal. Porque si fuese joven y no estuviese al margen de la literatura como lo está ahora, habría que molestarle en serio..."

Nótese que todos estos jóvenes intelectuales de los años veinte consideran al popular novelista una especie de fósil estético. $\mathrm{Y}$ así lo manifiestan abiertamente en una revista en la que se insertan en ocasiones textos de don Armando ${ }^{5}$ La Gaceta Literaria, que es el buque insignia de la nueva oleada intelectual de fines de los años veinte. La Gaceta..., había decidido encuestar a sus más jóvenes colaboradores con motivo del homenaje a Don Armando que estaba auspiciando, entre otros medios, La Correspondencia Militar.

La actitud despegada y hasta hostil de los nuevos escritores no se manifiesta sólo en las páginas de La Gaceta Literaria - que intentará exculpar a sus "muchachos" ante las protestas de algunos lectores más aficionados a la obra de don Armando (v. La Gaceta... del 15 de febrero de 1928, p. 1)- sino en las críticas que este nuevo plantel de intelectuales dedica al asturiano. Ahí esta, por ejemplo, la crítica que Rafael Cansinos-Assens dedica a Palacio Valdés. Entre otras lindezas, afirma: "Actualmente don Armando continúa siendo ajeno a la evolución de la novela y sin contacto alguno espiritual con los nuevos escritores, dando la impresión de un rezagado, de un superviviente" (17).

Asegura el crítico que Palacio Valdés carece de firme criterio ideológico (17) y lo separa radicalmente de Galdós, recordado a menudo por los jóvenes; y estima que el asturiano es patriarcal sólo por la edad, no por su posición en las letras; refleja y defiende la moral burguesa, y su plácido rostro esconde a un firme reaccionario. Su reciente novela Santa Rogelia "muestra la indigencia ideológica y ética de esa clase social [burguesa] para la que cada día más exclusivamente parece escribir el autor" (28).

Mientras tanto, las revistas culturales de fines de los años veinte recogen noticias sobre el éxito de Palacio Valdés en distintos países; la misma Gaceta Literaria se hace eco en 1929 del largo artículo que Bernardo Sansiventi dedica en Italia a don Armando y, en menor medida, a otros (15, abril, 1929, p. 6); o L. Ambruzzi

${ }^{5}$ Por ejemplo: en este mismo número de La Gaceta Literaria aparece una colaboración de Palacio Valdés sobre el cine ( p. 3). 
comenta que las novelas del asturiano son buen negocio para los editores en cualquier idioma que se presenten (15, diciembre, 1929)...

La presencia de Palacio Valdés en la prensa coetánea norteamericana ha sido objeto de varios estudios recientes, como ya he indicado. Mercedes Caballer ha mostrado el impacto que las reseñas de William D. Howells en Harper's New Monthly Magazine tuvieron en el público norteamericano y su contribución a las importantes tiradas que obtuvieron sus obras traducidas. Como consecuencia, "Armando Palacio Valdés es el escritor español del siglo XIX de quien se publica un mayor número de obras en Estados Unidos" (Caballer 293).

\section{Don Armando y las mujeres}

Según lo que he anotado más arriba, Palacio Valdés fue aun autor considerado disolvente y peligroso cuando joven; y sin embargo, acaba por volverse blando y sin aristas, afín a clérigos e inocentes señoritas ${ }^{6}$ según las estimaciones de ciertos intelectuales en la prensa de la Edad de Plata. Esteban Salazar Chapela decía en La Gaceta Literaria de 1/2/1928 (n. 27, p. 1):

"La literatura de Armando Palacio Valdés es una literatura de algodón en rama. Blanca, blanda, sin consistencia, insulsa. Muy propia para sus lectores, señoritas y clérigos con espíritu de algodón en rama".

Precisamente, obras de nuestro autor forman parte en los años veinte de colecciones dirigidas a alimentar los sueños de las inocentes jovencitas, como "La novela rosa", que también incluye obras y adaptaciones de otros autores aptos para públicos ingenuos como los hermanos Serafín y Joaquín Álvarez Quintero, en versión de la joven periodista María Luz Morales.

Y desde luego, no debe olvidarse que a esa colección van a parar textos que el Padre Ladrón de Guevara consideraba desaconsejables moralmente: La hermana San Sulpicio, por ejemplo. Según el religioso, esta novela constituye "una ironía volteriana"; pero lo cierto es que aparece en la colección "La novela rosa" como número extraordinario (E256) en octubre de 1932 Valdés por ese entonces es enorme y la propaganda avisa: "encargue a tiempo un ejemplar a su librero, porque esta edición se agotará rápidamente".

\footnotetext{
${ }^{6}$ La narrativa al gusto de los sacerdotes parece de poca enjundia a muchos intelectuales europeos del primer tercio del siglo XX; por ejemplo: en 1919, Herman Hesse 67 hace hablar a uno de sus personajes de "la típica historia de curas, dulzona, falsa y sentimentalona con fondo muy edificante".

${ }^{7}$ Veo la publicidad correspondiente en el volumen de S. Y J. Álvarez Quintero: Las de Caín, novelada por María Luz Morales y aparecida como edición especial de "La novela rosa" en Septiembre de 1932.
} 
Así, don Armando, tan liberalote y divorciado de la crítica biempensante treinta años atrás, acaba por encajar en el horizonte de clérigos y señoritas a ojos de los intelectuales de la Edad de Plata.

Lo cierto es que las actitudes del novelista respecto a la religión sufrieron un cambio a fines de los años noventa; pero también hubo un cambio en la perspectiva que adoptó respecto a la cuestión femenina, un cambio que lo aproximó a una sensibilidad más moderna. Guadalupe Gómez- Ferrer ha observado la evolución al respecto y explica:

\begin{abstract}
"Don Armando fue siempre partidario de la mujer doméstica que en su obra tiene un papel referencial ${ }^{8}$; la mujer alma del hogar, norte y sosiego del varón, responde a un arquetipo tradicional, "preindustrial" podría decirse incluso. [...] Buen exponente de esta mujer doméstica, "ángel del hogar" en expresión de la época, son Marta (Marta y María), Maximina (Riverita-Maximina), Cecilia (El cuarto poder)..., y tantas otras más.
\end{abstract}

Pero la profesora Gómez Ferrer ("Los arquetipos femeninos socializados"... 39) considera que, a partir de 1899, si bien don Armando continúa apreciando las excelencias de la mujer doméstica, se muestra receptivo a los aires de renovación en lo que al papel de la mujer se refiere. Y ello se hace evidente en el capítulo titulado "El gobierno de las mujeres" de su obra Papeles del Doctor Angélico (1911), donde se defiende la capacidad política de las mujeres. El alegato de un personaje femenino, la escritora Carmen Salazar, en dicha obra, es antecedente del texto que publica el novelista veinte años más tarde, cuando las Cortes de la II República discuten el reconocimiento de los derechos políticos de las mujeres: El gobierno de las mujeres. Ensayo histórico de la política femenina, en que se hace una revisión histórica y se ofrece un repertorio de grandes gestoras de los destinos colectivos (Gómez Ferrer, “ Palacio Valdés, de escritor misógino...”, 24 y ss).

Así, habría un progresivo acercamiento a la línea protofeminista en la obra de don Armando. Pero nótese que la simpatía con que las lectoras, cultivadas o no, han leído las novelas del asturiano, es muy temprana. En 1903, Gregorio Martínez Sierra afirmaba que las mujeres se incluyen en el público discreto y callado que lee las novelas de Palacio Valdés, cuyos libros se ven con frecuencia en manos femeninas (La Lectura, pp. 401-3, $\mathrm{n}^{\circ} 1$ de 1903). Ya en los años veinte dos mujeres cultivadas sienten que el género femenino está en deuda con el escritor y así lo manifiestan; me refiero a dos artículos, uno de Felisa Rogerio en la Revista de Segunda Enseñanza y otro de Leah R. Wagenheim en la revista Hispania.

${ }^{8}$. Véase a este respecto, Gómez Ferrer, 2002, especialmente, pp. 39 y ss. La afinidad de Palacio Valdés con los modelos femeninos de carácter doméstico y su aplauso a la mujer tradicional se consideran también en Carmen Servén, 2002. 
El de Felisa Rogerio, aparecido en 1925, es el texto de una conferencia pronunciada ante la Asociación de Antiguos Alumnos del Instituto San Isidro de Madrid. Se titula "La mujer en las novelas de Palacio Valdés"; y muestra profunda admiración y agradecimiento al escritor. Considera que en su obra hay mujeres "delicadamente forjadas" que parecen arrancadas del entorno real $(306)^{9}$, revisa el perfil de varias de ellas y espera que sus palabras basten "para que veáis como a Palacio Valdés le debemos las mujeres gratitud inmensa por esa admiración, por ese respeto que por nosotras siente y que se demuestra en sus heroínas" (313); además en todas ellas "hay algo que admirar y aprender" (313). La señorita Felisa Rogerio Sánchez evoca también la figura del autor, un anciano sereno y digno, y sienta feliz distancia entre sus obras, que muestran "nuestros retratos tales como el original es", y otra clase de literatura que presenta una cara más desagradable de la mujer, una "literatura chocarrera y liviana". Termina con palabras encendidas: "[don Armando] supo del corazón de la mujer; sondeó en él y nos lo ofreció, palpitante a veces; pero acertó a poner el más dolorido en un relicario tan bien trabajado, que más que análisis, lo que el maestro hizo parece ofrenda y culto" (313).

El sentido elogio de la joven señorita Felisa Rogerio-Sánchez, hija del conocido catedrático del mismo apellido, se orienta hacia la admiración rendida y el agradecimiento al igual que el artículo-entrevista que Leah $\mathrm{R}$. Wagenheim dedica al escritor en la revista Hispania; pero este último es menos sentimental y más analítico. Aparecido en 1929, cuando el novelista tiene ya 76 años, es producto de una entrevista que mantienen la lectora y el autor en la villa "Marta y María" de Cap Breton. Tras declarar: "I have always admired his woman characters" (443), la entrevistadora deja constancia de que entre todas sus heroínas Palacio Valdés prefiere a Santa Rogelia; por otra parte, en el terreno de lo femenino él destaca "El gobierno de las mujeres" en Papeles del doctor Angélico, como exponente de sus ideas sobre la mujer (443).

Tras retratar la apacible vida cotidiana del autor, Wagenheim selecciona e inserta en su texto ciertos fragmentos del escritor que, al parecer de la entrevistadora, muestran el talante feminista del autor. Y éste declara: "Soy más feminista que las mismas señoras sufragistas de Inglaterra. Ellas no piden más que el voto; yo pido toda la política para la mujer y también la administración de justicia (446). La entrevista concluye afirmando: "Palacio Valdés insists that woman is more moral tan man", lo que coloca al autor en sintonía con discursos de género propios de la segunda mitad del XIX ${ }^{10}$, discursos que la entrevistadora debe considerar el colmo de la modernidad.

${ }^{9}$ Lo que contrasta con las estimaciones de críticos tan cualificados como Brian Dendle (60), para quien "los personajes femeninos [de Palacio Valdés] poseen a menudo las exageradas virtudes y vicios de los protagonistas de folletín".

${ }^{10}$ La superioridad moral e las mujeres es un tópico que se abre paso a lo largo del siglo XIX y que se vincula a roles femeninos domésticos, según Jagoe 26. 
La entrevista con Wagenheim ofrece motivos de reflexión; por una parte hallamos extremos que revelan la pertenencia de don Armando a la generación de escritores de la Restauración y por otra observamos que el novelista insiste en exaltar a una de sus heroínas más controvertidas. En cuanto a la pertenencia a cierta generación que escribía en medio de una defensa de la superior moralidad femenina y en consonancia con ello promovía el modelo femenino de mujer doméstica y capaz de asumir la educación moral de sus hijos, nótese que Palacio Valdés estuvo lejos de las posiciones reivindicativas y protofeministas; así como la condesa de Pardo Bazán reclamó para la mujer un destino y una responsabilidad propios, una educación menos incapacitante para la autonomía personal y una mayor libertad de elección, Palacio dedicó sus desvelos a fraguar heroínas empapadas de domesticidad, mujeres corrientes pero de encanto inolvidable con quienes las lectoras podían identificarse. De hecho, él mismo escribía a Leopoldo Alas: "[La Pardo] no me perdona el haber hecho la apoteosis de la mujer vulgar. No me pesa. Lo que yo hubiera querido era poder esculpir esa apoteosis en un libro profundamente como la tengo esculpida en el alma"11. De Creer a Ángel Cruz Rueda (168), las obras de Palacio Valdés influyeron mucho en las mujeres, de las que continuamente recibía cartas y confidencias.

Y en cuanto a la abierta simpatía que don Armando mostraba por Santa Rogelia, recuérdese que es probablemente su personaje más vituperado. Cansinos-Asséns, intelectual señalado de la Edad de Plata, hacía una valoración muy negativa, según hemos visto más arriba; la consideraba una "santa burguesa" sin fundamento ético alguno, carente de todo espíritu evangélico y a su autor un retrógrado integral; la novela Santa Rogelia es, según Cansinos, "un folletín escrito en ese rápido estilo que requiere el género, sin que el análisis psicológico ni la preocupación retórica obsten al interés del argumento" y muestra la indigencia ética y estética propia de la burguesía a que se destina tal lectura (Cansinos 28).

Así, pese a que Wagenheim y Rogerio Sánchez glosan la actitud de Palacio Valdés hacia la mujer, no hemos de concluir obligatoriamente que don Armando fue un adalid de la causa feminista, sino un novelista admirado y leído por las mujeres; y que constituyó un tópico en la Edad de Plata considerar que "sobresalió Palacio Valdés en la descripción y creación de caracteres, sobre todo femeninos" (Fernández Almunzara 433), como afirmó un artículo publicado a su muerte en 1938.

Como quiera que sea, en los años veinte y treinta, el anciano don Armando era un hombre muy estimado por las mujeres, según se desprende de su presencia en publicaciones a ellas destinadas y como se deduce de los homenajes que ellas quisieron tributarle.

El Hogar y la Moda, la revista femenina de más larga vida en la historia de España, un título de referencia en lo que se refiere a esta clase de publicaciones, fue

${ }^{11}$ Carta del 23-III-1887 escrita por Palacio Valdés a Clarín. 
dirigida en los años veinte por una joven brillante: María Luz Morales. Esta directora consolidó la fama de la revista: incluyó firmas jóvenes y conocidas, como la de Carmen de Burgos, se inclinó hacia un modelo de mujer trabajadora y moderna, comentó modos y modas, e insertó en sus páginas frecuentes textos de animación a la lectura femenina y de entrevistas con conocidos escritores: Martínez Sierra, Linares Rivas, Jacinto Benavente...y también Armando Palacio Valdés (25V-1924, p. 7). Así, don Armando formaba parte del imaginario cultural que difundía El Hogar y la Moda.

Por su parte, la revista Lecturas, que constituía una publicación ligada a la empresa de El Hogar y la Moda ${ }^{12}$ y se destinaba a alimentar la afición lectora de las mujeres, con tirada y aparición independiente, insertaba con frecuencia textos de Palacio Valdés. Solía incluir en formato seriado novelas muy conocidas, y entre ellas apareció La hermana San Sulpicio (1927). También ofreció cuentos de Palacio Valdés, extractos de sus novelas (de La alegría del capitán Ribot en agosto de 1921) y artículos conmemorativos en el aniversario de la publicación de algunas de sus novelas más conocidas (abril de 1937: celebra el cincuentenario de la aparición de Maximina).

Y la vida cotidiana del escritor era objeto de curiosidad en publicaciones de interés general. En La Estampa (Matilde Muñoz, 3-I-1928) se describe ese rincón "modesto e íntimo" donde trabaja y vive el maestro, se evocan simultáneamente el sol en su ventana y su "prosa transparente" y se construye todo el texto a partir de una entrevista con su esposa. Se sigue por tanto un modelo de periodismo cultural que popularizó La Gaceta Literaria en los años veinte y que consistía en entrevistas con las mujeres de los grandes hombres o los genios para mostrar la cara hogareña de los mismos.

Pero el especial vínculo que en la Edad de Plata se estableció entre don Armando y las mujeres se hace evidente, sobre todo, al considerar los homenajes que ellas proyectaron tributarle. Sobre tales homenajes hay abundante testimonio en la prensa del periodo.

Tenemos noticia de varios homenajes tributados a Palacio Valdés: el celebrado en la Universidad de Oviedo en que participaron varios conocidos intelectuales; el organizado con motivo de la inauguración del teatro que lleva su nombre en Avilés, y del que da buena cuenta La Esfera entre la prensa nacional el 21-8-1920; el promovido por La Correspondencia militar en enero de 1928 y que fue secundado por otros órganos de prensa...pero sobre todo vamos a tener en cuenta los que las mujeres le dedicaron en 1935.

${ }^{12}$ Sobre la revista Lecturas, su alcance y su función, proporciona datos interesantes Ángela Ena. 
Hubo entonces una "fiesta de gratitud" a don Armando, el "hombre inteligente y bueno que tan admirablemente ha sabido ensalzar a la mujer", en la Rosaleda de El Retiro. La gestora fue la escritora María Valero y a ella se adhirieron numerosas asociaciones femeninas; hubo un desfile de mujeres que dejaban cada una su notita amable en el cesto de flores colocado junto al novelista. Del evento da buena cuenta la revista Mundo Femenino el 1-5-1935.

Pero además, a primeros de noviembre de ese mismo año, Mundo Femenino ${ }^{13}$ da noticia del homenaje proyectado por la ANME (Asociación Nacional de Mujeres Españolas), de la que es órgano esta revista. Se trataba de erigir un monumento al escritor en Madrid, según se explica en esa revista el 1-XI-35 y el 1-III-36. Había que recaudar dinero para financiar una figura plástica de la Hermana San Sulpicio, y el hecho es que gran parte de la prensa se involucró en la empresa. El propio Ramiro de Maeztu da cuenta en el $A B C$ de 21-VI-36 de que la Comisión Ejecutiva de Mujeres Españolas solicita su colaboración en la difusión del proyectado homenaje, del que se hace eco gustosamente; Maeztu deja constancia de que el mundo "no es ya el plácido de nuestras clases medias, que gusta de pintar el maestro asturiano; se refiere al "equilibrio armónico" de Don Armando; y comparte la perspectiva según la cual "el sexo femenino tiene que estar agradecido al patriarca de nuestras letras, por haber sabido idealizarlo en sus novelas".

Así, las mujeres de la Edad de Plata agasajaron y agradecieron repetidamente sus obras al escritor; y en su marcha arrastraron voluntades masculinas.

\section{Conclusión}

La prensa de la Edad de Plata muestra que Palacio Valdés fue un escritor muy popular y controvertido en los últimos años de su vida. El estudio de sus obras no puede ejecutarse al margen de la recepción de las mismas, que ilumina el sentido otorgado a esta producción literaria por sus coetáneos. Iglesia y Asociaciones Femeninas fueron colectivos especialmente activos en torno a la interpretación de las obras de don Armando. Y su intervención debe ser recordada al evaluar la proyección actual de este corpus literario.

\section{Obras citadas}

ABAD, Carlos María. "La literatura de hoy. Novelistas católicos: Armando Palacio Valdés", Razón y Fe, 68, enero 1924, pp. 45-63.

CABALlER DONDARZA, Mercedes. La narrativa española en la prensa estadounidense. Madrid: Iberoamericana, 2007.

${ }^{13}$ En esta revista colaboró ocasionalmente el novelista asturiano. Su artículo "Un oasis", aparecido el 1-XI-35 es un alegato a favor de la mujer y una brevísima revisión histórica de su precaria posición. 
CAMPAl FernánDEZ, José Luis. "Bibliografía sobre Armando Palacio Valdés", Archivum LII-LIII (2002-2003), pp. 31-101.

CANSINOS-ASSENS, Rafael. La nueva literatura.IV. La evolución de la novela (1917-1927).

CAPEllán GonZalo, Ángel. "William Dean Howells and Armando Palacio Valdés: A Literary Friendship", Revista de Estudios Hispánicos, 10 (3) 1976, pp. 451-471.

CRUZ RUEDA, Ángel. Armando Palacio Valdés. Su vida y su obra. Madrid: SAETA, 1949.

DENDLE, Brian J. "Armando Palacio Valdés, el asturiano universal. Una visión de conjunto". Palacio Valdés en Asturias. Actas del II Congreso Internacional Armando Palacio Valdés y su obra celebrado en Entralgo - Laviana (4, 5, 6 y 7 de octubre de 2005), ed. Francisco Trinidad. Laviana: Excmo. Ayuntamiento de Laviana/Centro de Interpretación Armando Palacio Valdés, 2006, pp. 57-70.

ENA BORDONADA, Ángela. "Concha Espina en la revista Lecturas", conferencia pronunciada el 10 de Diciembre de 2009 en el Seminario Internazionale En prensa: escritoras y periodistas en España (1900-1939) de L'Università degli studi di Bergamo. Actualmente en prensa.

FernándeZ AlmunZara, E. Palacio Valdés (1853-1938)", Razón y Fe, abril de 1938, pp. 422-435.

FERNÁNDEZ CIFUENTES, Luis: Teoría y mercado de la novela en España del 98 a la República. Madrid, Gredos, 1982.

GÓMEZ-FERRER MORANT, Guadalupe. "Los arquetipos femeninos socializados por la novela realista" en Hombres y mujeres: el dificil camino hacia la igualdad. Madrid: Editorial Universidad Complutense de Madrid, 2002.

GÓMEZ-FERRER MORANT, Guadalupe. "Armando Palacio Valdés y la civilización de su tiempo: la sensibilidad de un novelista". Palacio Valdés. Un clásico olvidado (1853-2003). Actas del Congreso celebrado en Laviana-Entralgo (2426 de septiembre de 2003), ed. Elena de Lorenzo Álvarez y Álvaro Ruiz de la Peña. Laviana: Excmo. Ayuntamiento de Laviana, 2005, pp. 131-166.

. Palacio Valdés, de escritor misógino a defensor de las mujeres políticas. El valor de la historia: homenaje al profesor Julio Aróstegui. Coord. por Jesús Antonio Martínez Martín, Eduardo González Calleja, Sandra Souto Kustrín, Juan Andrés Blanco Rodríguez, 2009, pp.. 227-236.

GONZÁLEZ BLANCO, Andrés. "El patriarca de la novela española. Don Armando Palacio Valdés", Nuestro tiempo, no 307, agosto, 1924, pp. 149-165.

HESSE, Hermann. Demian (1919). Madrid: Alianza, 2003.

JAGOE, Catherine, Alda Blanco y Cristina Enríquez de Salamanca. La mujer en los discursos de género. Barcelona: Icaria, 1998.

LAdRÓN DE GuevarA, Pedro. Novelistas malos y buenos. Bilbao: El Mensajero del Corazón de Jesús, 1933 ( $4^{\mathrm{a}}$ ed. Completa). 
OLEZA, Joan: "El debate en torno a la fundación del realismo. Galdós y la poética de la novela en los años setenta". Actas del Quinto Congreso Internacional de Estudios Galdosianos (1992), vol. II. Gran Canaria: Excmo. Cabildo Insular de Gran Canaria, 1995, pp. 257-266.

PALACIO VAldÉS, Armando. La fe. Ed. Etelvino González López. Laviana: Ediciones del Centro de Interpretación Armando Palacio Valdés, 2010.

Rogelio SÁnchez, María Felisa. "La mujer en las novelas de Palacio Valdés", Revista de Segunda Enseñanza, febrero de 1925, pp. 304 y ss.

SERVÉn DíEZ, Carmen. "La Ilustración Católica frente a la novela: 1877-1894", Revista de Literatura (CSIC), LXIV, 127, 2002, pp.219-234.

SERVÉN DÍEZ, Carmen: La relación entre el amor y el dinero en la novelística de la Restauración: Valera, Pereda, Pérez Galdós, Clarín, Pardo Bazán ,Palacio Valdés. Madrid: Universidad Complutense de Madrid , 2002 (recurso electrónico)

UnAMUNO, Miguel de. "Por Armando Palacio Valdés", en Homenaje de la Universidad, Oviedo, 5 de abril de 1906; también en Obras completas. III. Nuevos ensayos. Madrid: Escelicer, 1966, pp. 1108-9.

WAGENHEIM, Leah R. "A chat with Armando Palacio Valdés on Feminism", Hispania, XII, $\mathrm{n}^{\mathrm{o}}$ 5, nov. 1929, pp. 439 y ss.

ZoLA, Émile: El naturalismo. Ed. de Laureano Bonet. Barcelona: Península, 1988. 